\title{
A Country-Level Decision Support Framework for Self-Assessment of E-Commerce Maturity
}

\author{
Faramak Zandi
}

Department of Industrial Engineering, Faculty of Technology and Engineering, University of Science and Culture, Tehran, Iran. Email: zandi@iust.ac.ir

Received January 26 ${ }^{\text {th }}, 2013$; revised March 27 ${ }^{\text {th }}, 2013$; accepted April 20 ${ }^{\text {th }}, 2013$

Copyright (C) 2013 Faramak Zandi. This is an open access article distributed under the Creative Commons Attribution License, which permits unrestricted use, distribution, and reproduction in any medium, provided the original work is properly cited.

\begin{abstract}
Countries need to be aware of the stage of their current e-Commerce maturity for choosing the right strategy to move forward. For this purpose, we develop a country-level decision support framework to determine maturation stage of e-Commerce in a country. At first, e-Commerce maturity scores of local e-Markets in each regional e-Market are calculated using a fuzzy bi-level Technique for Order Preference by Similarity to Ideal Solution (TOPSIS) method. Then, e-Commerce maturity scores of regional e-Markets in the country are determined based on a fuzzy bi-level fishbone diagram. After that, national e-Commerce maturity level is assessed using a three-level decision making model. The contribution of the proposed decision support framework is four folds: 1) it develops a fishbone diagram to a fuzzy bi-level environment; 2) it presents a country-level decision making model with three levels of local, regional, international e-Markets to assess country's e-Commerce maturity level; 3) it considers interdependencies between local, regional and international e-Markets; and 4) it synthesizes qualitative judgments and quantitative data of maturity criteria and sub-criteria. The results of this self-assessment can be used to analyze national e-Commerce strengths, weaknesses in e-Commerce development and move to the next level of e-Commerce maturity. Furthermore, it can be used as a device to transfer knowledge to developing countries. We present a case study to determine US e-Commerce maturity level.
\end{abstract}

Keywords: E-Commerce Maturity; Fuzzy Bi-Level Fishbone Diagram; Country-Level Decision Making Framework; Bi-Level TOPSIS

\section{Introduction}

E-Commerce is the buying and selling of product or service over electronic systems such as the Internet and other computer networks. Over the past several years many papers have focused on e-Commerce [1-8]. A number of further studies have applied e-Commerce adoption [9-15].

E-Commerce Maturity relates to development and growth, from an initial e-commerce state to an advanced e-Commerce state. Countries need to be aware of the stage of their current e-Commerce maturity for choosing the right strategy to move forward. It is impossible without having a national e-Commerce maturity self-assessment framework. Some models in current literature that have studied electronic commerce maturity are as follows: the e-Commerce maturity model [16], with three maturity stages (Experimentation, Ad-hoc implementation and Integration); Grant's Model [17] considers five maturity stages (immaturity, on the Internet, e-Com- merce provisional strategy decided, ready to implement and integrated and effective e-Commerce); the maturity model of McKay, et al. [18] with the six maturity stages (no presence, experimental on-line presence, interactive online presence, e-Commerce, Internal integration and external integration); the model of Earl [19], with six maturity stages (external communication, Internal communication, e-Commerce, e-Business, e-Enterprise and transformation); the SOG-e Model [20] also with six maturity stages (no presence, static online presence, interactive online presence, Internet commerce, integrated organization and extended enterprise); the model of Rayport and Jaworski [21], this model outlines four phases (broadcast, interaction, transaction and collaboration); the model of Rao, et al. [22] also suggests four stages: (presence, portals, transaction integration and Company integration) and the model of Chan and Swatman [23], with four stages of growth (initial e-Commerce, centralized e-Commerce, looking inward for benefits and global e-Commerce). Indeed, these studies are performed 
to measure the maturity of an organization with 3 - 6 maturity stages. A number of further studies have focused on self-assessment and maturity models [24-29]. But, there is not any mathematical model to measure e-Commerce maturity with parametric maturity stages.

Furthermore, mainstream researches have focused on e-Commerce maturity and self-assessment models in small and medium-sized enterprises. There is a gap in country self-assessment for a comprehensive, systematic and regular review of e-Commerce maturity.

Despite the following papers in current literature, there is not any country-level decision making model to assess the current status of e-Commerce maturity in countries: US [30]; UK [31]; Brazil [32]; Mexico [33]; in Greece [34]; South Korea [35]; Singapore [36-38]; Hong Kong [39]; China [40-43]; India [44]; Malaysia [45,46]; developing countries [47] and global e-Commerce researches [48-52]

For this purpose, we present a three-level national e-Commerce self-assessment framework where: 1) it addresses the gaps in the effective self-assessment of country-level e-Commerce maturity; 2) it considers three levels of local, regional, international e-Markets along with interdependencies between them in the national e-Commerce self-assessment process; 3) it synthesizes qualitative judgments and quantitative data of maturity criteria and sub-criteria; and 4) it considers fuzzy logic and fuzzy sets to represent ambiguous, uncertain or imprecise information. The results of this eCommerce maturity self-assessment allow a country to discern clearly its strengths and areas in which improvements can be made and culminate in planned improvement actions that are then monitored for progress.

This paper is organized into five sections. We present the mathematical notations and the details of the proposed framework in Sections 2 and 3. In Section 4 we present a case study to demonstrate the applicability of the proposed framework and in Sections 5 and 6 we present our concluding remarks and acknowledgement.

\section{Mathematical Notations and Definitions}

Let us introduce the following mathematical notations and definitions:

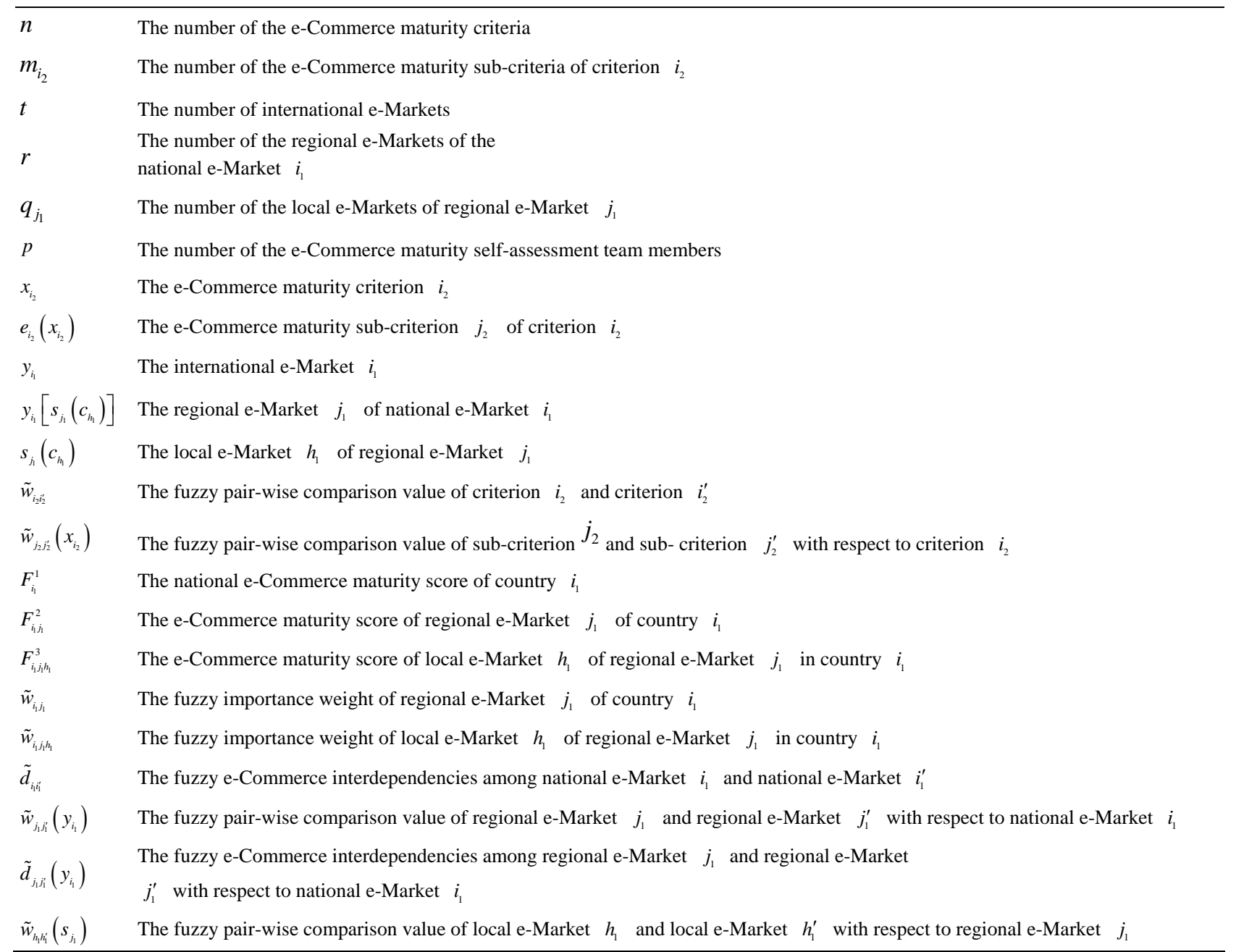




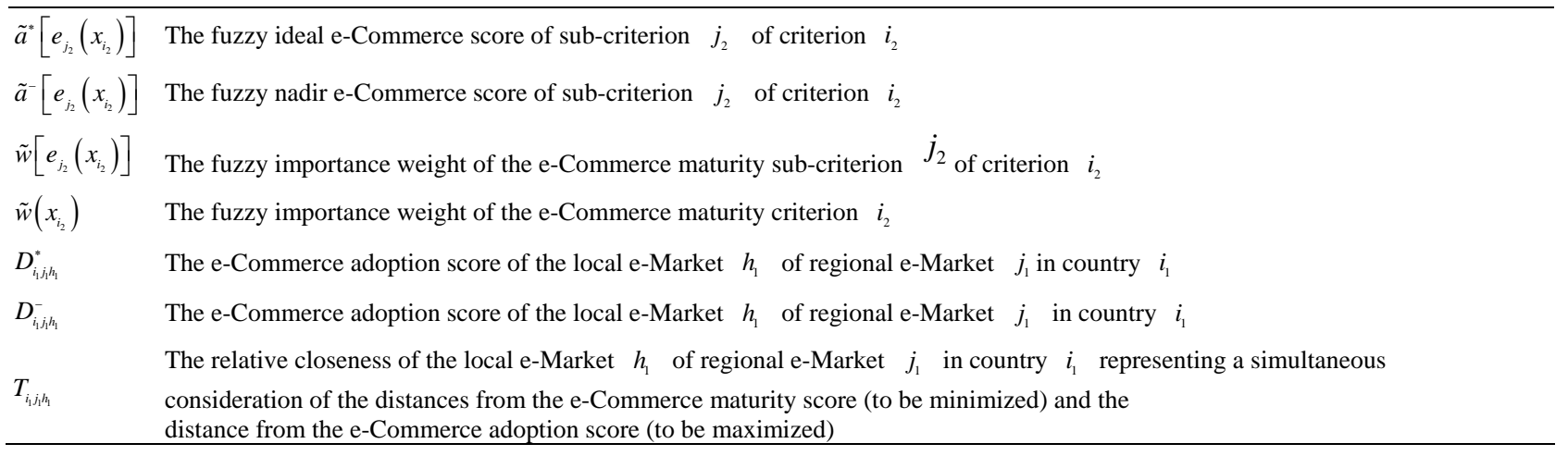

\section{Proposed Framework}

We propose the framework depicted in Figure 1 to determine an e-Commerce maturity level of a country. The proposed framework consists of three main phases modularized into a series of processes and procedures.

The proposed framework is a comprehensive and structured framework designed to capture the subjective and objective judgments associated with qualitative and quantitative criteria in fuzzy multi-criteria e-Commerce maturity self-assessment problems.

Phase 1: Define the e-Commerce maturity self-assessment team and e-Commerce maturity criteria

In this phase, the e-Commerce maturity self-assessment team and criteria are defined as follows:

Process 1.1: Establish the e-Commerce maturity selfassessment team

We begin the self-assessment framework by establishing an e-Commerce maturity self-assessment team. Let us assume that we form an e-Commerce maturity selfassessment team with $p$ members as follows:

$$
\underline{T(\mathrm{CM})}=\left[M_{1}(\mathrm{~cm}), M_{2}(\mathrm{~cm}), \cdots, M_{p}(\mathrm{~cm})\right]
$$

Process 1.2: Draw the fuzzy bi-level fishbone diagram

In this process, the team draws the following fuzzy bi-level fishbone diagram:

Procedure 1.2.1: Draw the first level of the bi-level fishbone diagram

In this procedure, the country is categorized into several regional e-Markets and each regional e-Market is further categorized into several local e-Markets in the first level of the bi-level fishbone diagram. This bi-level diagram presented in Figure 2. Let us consider the following $t$ national e-Commerce interdependencies, $r$ regional e-Markets and $q_{j_{1}}$ local e-Markets as follows: International e-Markets of country

$$
i_{1}=\left[y_{1}, y_{2}, \cdots, y_{t}\right]
$$

Regional e-Markets of the national e-Market

$$
i_{1}=\left[y_{i_{1}}\left(s_{1}\right), y_{i_{1}}\left(s_{2}\right), \cdots, y_{i_{1}}\left(s_{j_{1}}\right), \cdots, y_{i_{1}}\left(s_{r}\right)\right]
$$

Local e-Markets of the regional e-Market

$$
j_{1}=\left[y_{i_{1}}\left[s_{j_{1}}\left(c_{1}\right)\right], y_{i_{1}}\left[s_{j_{1}}\left(c_{2}\right)\right], \cdots, y_{i_{1}}\left[s_{j_{1}}\left(c_{q_{j_{1}}}\right)\right]\right]
$$

Procedure 1.2.2: Draw the second level of the bi-level fishbone diagram

In this procedure, the self-assessment team identifies a set of e-Commerce maturity criteria. Each e-Commerce maturity criterion is further categorized into several e-Commerce maturity sub-criteria in the second level of the bi-level fishbone diagram. This diagram presented in Figure 2. Let us consider the following n e-Commerce maturity criteria and mi sub-criteria as follows:

The e-Commerce maturity criteria of the local e-Markets:

$$
\underline{X}=\left[x_{1}, x_{2}, \cdots, x_{j_{2}}, \cdots, x_{n}\right]
$$

The e-Commerce maturity sub-criteria of the criterion:

$$
j_{2}=\left[e_{1}\left(x_{j_{2}}\right), e_{2}\left(x_{j_{2}}\right), \cdots, e_{m_{j_{2}}}\left(x_{j_{2}}\right)\right]
$$

Phase 2: Calculate the fuzzy importance weight of the elements in the bi-level fishbone diagram

In this phase, the fuzzy importance weight elements of the bi-level fishbone diagram are then calculated by the following processes:

Process 2.1: Calculate the fuzzy importance weight of the e-Markets in the first level of the bi-level fishbone diagram

In this process, the fuzzy importance weight of the regional and local e-Markets are then calculated in the first level of the bi-level fishbone diagram by the following procedures:

Procedure 2.1.1: Construct the fuzzy pairwise comparison matrices in the first level of the bi-level fishbone diagram

In this procedure, the e-Commerce maturity self-assessment team compares pairs of the regional e-Markets with respect to their importance. Similarly, pairs of the local e-Markets in each regional e-Market are also compared with respect to their importance. The relative importance values are determined with Saaty's $\tilde{1}-\tilde{g}$ scale 


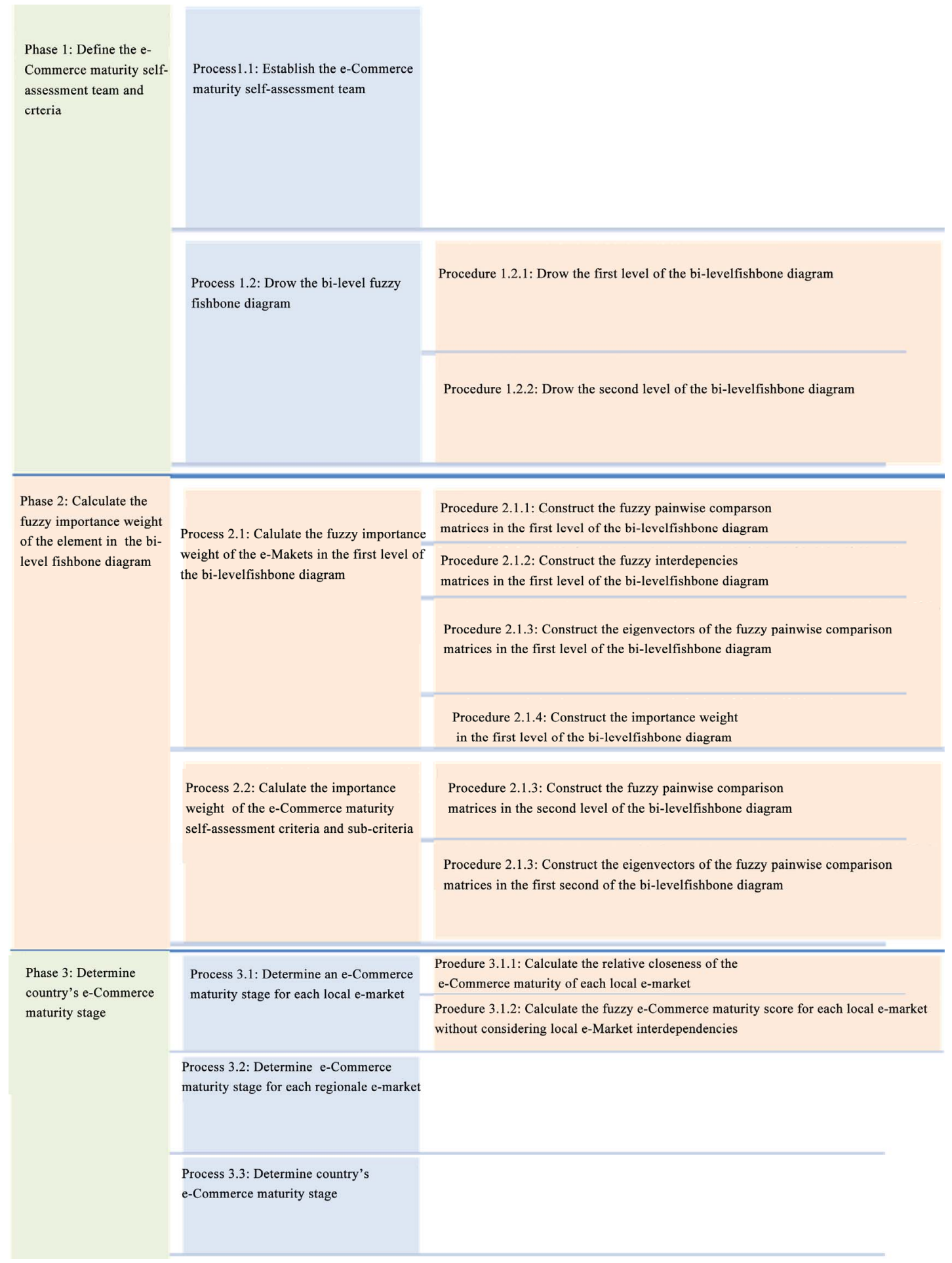

Figure 1. The proposed framework for national e-Commerce maturity self-assessment.

where a score of $\tilde{1}$ represents equal importance and a score of $\tilde{9}$ indicates an extreme importance. The fuzzy pairwise comparison matrices of the regional and local e-Markets evaluated by the team are shown in Tables 1 and 2.

Procedure 2.1.2: Construct the fuzzy interdependen- cies matrices in the first level of the bi-level fishbone diagram

In this procedure, the e-Commerce maturity self-assessment team constructs the matrices of fuzzy interdependencies for the national, regional and local e-Markets as shown in Tables 3-5: 


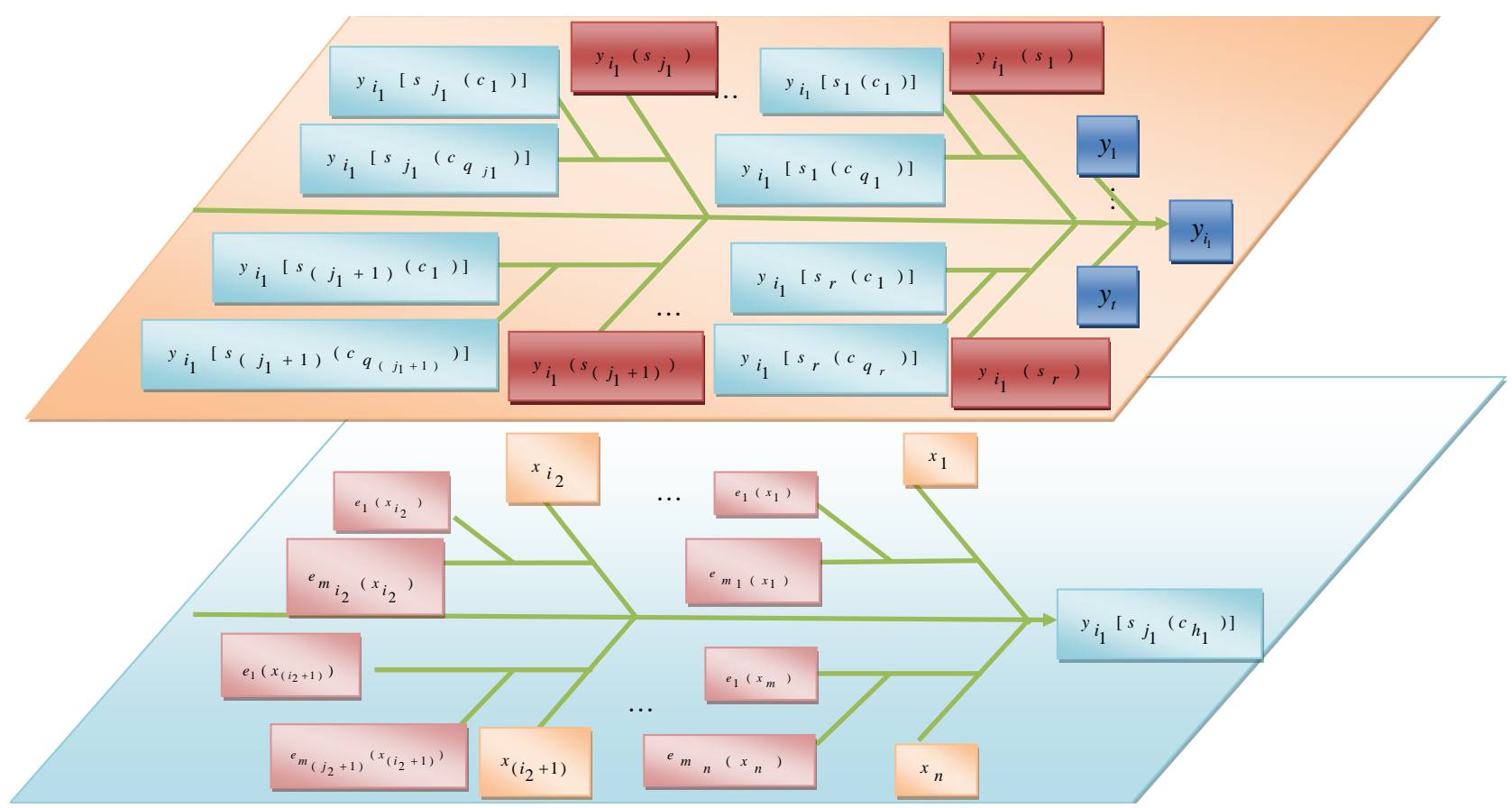

Figure 2. The e-Commerce maturity self-assessment criteria and sub-criteria in the fuzzy bi-level fishbone diagram.

Table 1. The fuzzy pairwise comparison matrix of the regional e-Markets.

\begin{tabular}{cccc}
\hline & $s_{1}\left(y_{i_{1}}\right)$ & $\cdots$ & $s_{r}\left(y_{i_{1}}\right)$ \\
\hline$s_{1}\left(y_{i_{1}}\right)$ & $\tilde{w}_{11}\left(y_{i_{1}}\right)$ & $\cdots$ & $\tilde{w}_{1 r}\left(y_{i_{1}}\right)$ \\
$\vdots$ & $\vdots$ & $\ldots$ & $\vdots$ \\
$s_{r}\left(y_{i_{1}}\right)$ & $\tilde{w}_{r 1}\left(y_{i_{1}}\right)$ & $\cdots$ & $\tilde{w}_{r r}\left(y_{i_{1}}\right)$ \\
\hline
\end{tabular}

Table 2. The fuzzy pairwise comparison matrix of the local e-Markets.

\begin{tabular}{|c|c|c|c|c|c|c|c|c|}
\hline & & \multicolumn{3}{|c|}{$s_{1}\left(y_{i_{1}}\right)$} & \multirow{2}{*}{$\begin{array}{l}\cdots \\
\cdots\end{array}$} & \multicolumn{3}{|c|}{$s_{r}\left(y_{i_{1}}\right)$} \\
\hline & & $C_{1}\left(s_{1}\right)$ & $\ldots$ & $C_{q_{1}}\left(s_{1}\right)$ & & $C_{1}\left(s_{r}\right)$ & $\ldots$ & $C_{q_{r}}\left(s_{r}\right)$ \\
\hline \multirow{3}{*}{$s_{1}\left(y_{i_{1}}\right)$} & $c_{1}\left(s_{1}\right)$ & $\tilde{w}_{11}\left(s_{1}\right)$ & $\ldots$ & $\tilde{w}_{1 q_{1}}\left(s_{1}\right)$ & & 0 & $\ldots$ & 0 \\
\hline & $\vdots$ & $\vdots$ & $\ldots$ & $\vdots$ & $\cdots$ & $\vdots$ & $\ldots$ & $\vdots$ \\
\hline & $c_{q_{1}}\left(s_{1}\right)$ & $\tilde{w}_{q_{1} 1}\left(s_{1}\right)$ & $\ldots$ & $\tilde{w}_{q_{1} q_{1}}\left(s_{1}\right)$ & & 0 & $\ldots$ & 0 \\
\hline$\vdots$ & $\vdots$ & & $\vdots$ & & $\cdots$ & & $\vdots$ & \\
\hline \multirow{3}{*}{$s_{r}\left(y_{i_{1}}\right)$} & $c_{1}\left(s_{r}\right)$ & 0 & $\ldots$ & 0 & & $\tilde{w}_{11}\left(s_{r}\right)$ & $\ldots$ & $\tilde{w}_{1 q_{r}}\left(s_{r}\right)$ \\
\hline & $\vdots$ & $\vdots$ & $\ldots$ & $\vdots$ & $\cdots$ & $\vdots$ & $\ldots$ & $\vdots$ \\
\hline & $C_{q_{r}}\left(s_{r}\right)$ & 0 & $\ldots$ & 0 & & $\tilde{w}_{q_{r} 1}\left(s_{r}\right)$ & $\ldots$ & $\tilde{w}_{q_{r} q_{r}}\left(s_{r}\right)$ \\
\hline
\end{tabular}

Table 3. The fuzzy e-Commerce interdependencies matrix among the national e-Markets.

\begin{tabular}{cccc}
\hline & $y_{1}$ & $\cdots$ & $y_{t}$ \\
\hline$y_{i_{1}}$ & $\tilde{d}_{i_{1}}$ & $\cdots$ & $\tilde{d}_{i_{n}}$ \\
\hline
\end{tabular}

Table 4. The fuzzy e-Commerce interdependencies matrix among the regional e-Markets.

\begin{tabular}{cccc}
\hline & $s_{1}\left(y_{i_{1}}\right)$ & $\cdots$ & $s_{r}\left(y_{i_{1}}\right)$ \\
\hline$s_{1}\left(y_{i_{1}}\right)$ & $\tilde{d}_{11}\left(y_{i_{1}}\right)$ & $\cdots$ & $\tilde{d}_{1 r}\left(y_{i_{1}}\right)$ \\
$\vdots$ & $\vdots$ & $\cdots$ & $\vdots$ \\
$s_{r}\left(y_{i_{1}}\right)$ & $\tilde{d}_{r 1}\left(y_{i_{1}}\right)$ & $\cdots$ & $\tilde{d}_{r r}\left(y_{i_{1}}\right)$ \\
\hline
\end{tabular}

Table 5. The fuzzy e-Commerce interdependencies matrix among the local e-Markets.

\begin{tabular}{|c|c|c|c|c|c|c|c|c|}
\hline & & \multicolumn{3}{|c|}{$s_{1}\left(y_{i_{1}}\right)$} & \multirow{2}{*}{$\begin{array}{l}\cdots \\
\ldots\end{array}$} & \multicolumn{3}{|c|}{$s_{r}\left(y_{i_{1}}\right)$} \\
\hline & & $c_{1}\left(s_{1}\right)$ & $\ldots$ & $c_{q_{1}}\left(s_{1}\right)$ & & $c_{1}\left(s_{r}\right)$ & $\ldots$ & $c_{q_{r}}\left(s_{r}\right)$ \\
\hline \multirow{3}{*}{$s_{1}\left(y_{i_{1}}\right)$} & $c_{1}\left(s_{1}\right)$ & $\tilde{d}_{11}\left(s_{1}\right)$ & $\ldots$ & $\tilde{d}_{1 q_{1}}\left(s_{1}\right)$ & & 0 & $\ldots$ & 0 \\
\hline & $\vdots$ & $\vdots$ & $\ldots$ & $\vdots$ & $\cdots$ & $\vdots$ & $\ldots$ & $\vdots$ \\
\hline & $c_{q_{1}}\left(s_{1}\right)$ & $\tilde{d}_{q_{1} 1}\left(s_{1}\right)$ & $\ldots$ & $\tilde{d}_{q_{1} q_{1}}\left(s_{1}\right)$ & & 0 & $\ldots$ & 0 \\
\hline \multirow[t]{2}{*}{$\vdots$} & $\vdots$ & & $\vdots$ & & $\cdots$ & & $\vdots$ & \\
\hline & $c_{1}\left(s_{r}\right)$ & 0 & $\ldots$ & 0 & & $\tilde{d}_{11}\left(s_{r}\right)$ & $\ldots$ & $\tilde{d}_{1 q_{r}}\left(s_{r}\right)$ \\
\hline \multirow[t]{2}{*}{$s_{r}\left(y_{i_{1}}\right)$} & $\vdots$ & $\vdots$ & $\ldots$ & $\vdots$ & $\ldots$ & $\vdots$ & $\ldots$ & $\vdots$ \\
\hline & $c_{q_{r}}\left(s_{r}\right)$ & 0 & $\ldots$ & 0 & & $\tilde{d}_{q_{r} 1}\left(s_{r}\right)$ & $\ldots$ & $\tilde{d}_{q_{r} q_{r}}\left(s_{r}\right)$ \\
\hline
\end{tabular}

Procedure 2.1.3: Calculate the eigenvectors of the fuzzy pairwise comparison matrices in the first level of the bi-level fishbone diagram

In this procedure, the e-Commerce maturity self-assessment team calculates the eigenvector of the fuzzy pairwise comparison matrices for the national, regional and local e-Markets shown in Figure 3. 


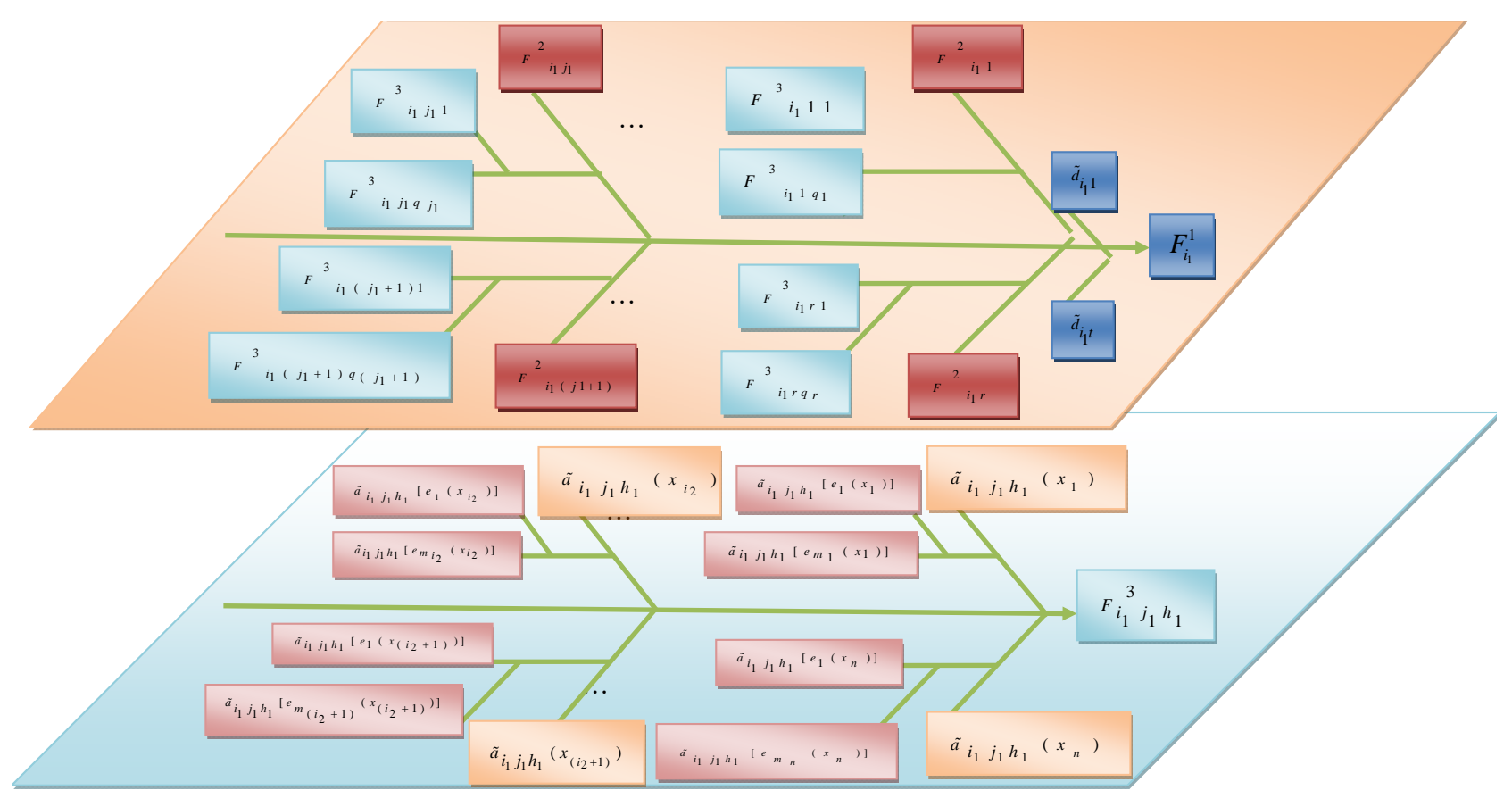

Figure 3. The fuzzy e-Commerce maturity self-assessment scores in the fuzzy bi-level fishbone diagram.

Procedure 2.1.4: Calculate the importance weight in the first level of the bi-level fishbone diagram

In this procedure, the team then calculates the importance weight of the national, regional and local e-Markets by multiplying the eigenvectors of the regional and local e-Markets by their respective fuzzy matrices of interdependencies.

Process 2.2: Calculate the importance weight of the e-Commerce maturity self-assessment criteria and subcriteria

In this process, the proposed approach is used to calculate the fuzzy importance weight of the e-Commerce maturity self-assessment criteria and sub-criteria using eigenvector in the second level of the fishbone diagram as follows:

Procedure 2.2.1: Construct the fuzzy pairwise comparison matrices in the second level of the fishbone diagram

In this procedure, the e-Commerce maturity self-assessment team compares pairs of the e-Commerce maturity criteria with respect to their importance. Similarly, pairs of the e-Commerce maturity sub-criteria in each e-Commerce maturity criterion are also compared with respect to their importance. The fuzzy pairwise compareson matrices of the e-Commerce maturity criteria and sub-criteria evaluated by the team are shown in Tables 6 and 7.

Procedure 2.2.2: Calculate the eigenvectors of the fuzzy pairwise comparison matrices in the second level of the bi-level fishbone diagram

In this procedure, the team then determines the importance weight of the e-Commerce maturity criteria and
Table 6. The fuzzy importance weight of the e-Commerce maturity self-assessment criteria.

\begin{tabular}{cccc}
\hline & $x_{1}$ & $\cdots$ & $x_{n}$ \\
\hline$x_{1}$ & $\tilde{w}_{11}$ & $\cdots$ & $\tilde{w}_{1 n}$ \\
$\vdots$ & $\vdots$ & $\cdots$ & $\vdots$ \\
$x_{n}$ & $\tilde{w}_{n 1}$ & $\cdots$ & $\tilde{w}_{n n}$ \\
\hline
\end{tabular}

Table 7. The fuzzy importance weight of the e-Commerce maturity self-assessment sub-criteria.

\begin{tabular}{ccccccccc}
\hline & & \multicolumn{3}{c}{$x_{1}$} & \multicolumn{3}{c}{$x_{n}$} \\
\cline { 2 - 8 } & & $e_{1}\left(x_{1}\right)$ & $\ldots$ & $e_{m_{1}}\left(x_{1}\right)$ & $\cdots$ & $e_{1}\left(x_{n}\right)$ & $\ldots$ & $e_{m_{n}}\left(x_{n}\right)$ \\
\hline & $e_{1}\left(x_{1}\right)$ & $\tilde{w}_{11}\left(x_{1}\right)$ & $\ldots$ & $\tilde{w}_{1 m_{1}}\left(x_{1}\right)$ & & 0 & $\ldots$ & 0 \\
$x_{1}$ & $\vdots$ & $\vdots$ & $\ldots$ & $\vdots$ & & $\vdots$ & $\ldots$ & $\vdots$ \\
& $e_{m_{1}}\left(x_{1}\right)$ & $\tilde{w}_{m_{1}}\left(x_{1}\right)$ & $\ldots$ & $\tilde{w}_{m_{1} m_{1}}\left(x_{1}\right)$ & & 0 & $\ldots$ & 0 \\
$\vdots$ & $\vdots$ & & $\vdots$ & & $\ldots$ & & $\vdots$ & \\
& $e_{1}\left(x_{n}\right)$ & 0 & $\ldots$ & 0 & & $\tilde{w}_{11}\left(x_{n}\right)$ & $\ldots$ & $\tilde{w}_{1 m_{n}}\left(x_{n}\right)$ \\
$x_{n}$ & $\vdots$ & $\vdots$ & $\ldots$ & $\vdots$ & $\ldots$ & $\vdots$ & $\ldots$ & $\vdots$ \\
& $e_{m_{n}}\left(x_{n}\right)$ & 0 & $\ldots$ & 0 & & $\tilde{w}_{m_{n}}\left(x_{n}\right)$ & $\ldots$ & $\tilde{w}_{m_{n} m_{n}}\left(x_{n}\right)$ \\
\hline
\end{tabular}

sub-criteria by calculating the eigenvector of the fuzzy pairwise comparison matrices for the e-Commerce maturity criteria and sub-criteria shown in Figure 3.

Phase 3: Determine the stage of national e-Commerce maturity

In this phase, the self-assessment team determines the stage of national e-Commerce maturity using the proposed fuzzy three-level decision making framework according to the following three processes: 
Process 3.1: Determine the e-Commerce maturity stage of each local e-Market

In this process, e-Commerce maturity stages for the local e-Markets of each regional e-Market is determined based on the third level of the proposed fuzzy three-level decision making framework according to the following two procedures:

Procedure 3.1.1: Calculate the relative closeness of the e-Commerce maturity of each local e-Market

In this procedure, the self-assessment team determines e-Commerce maturity stages of the local e-Markets of each regional e-Market based on its nadir and ideal scores (the fuzzy numbers of $\tilde{1}$ to $\tilde{9}$ scales). It measures the relative closeness or distances of the local eMarket from the e-Commerce maturity score (to be minimized) and from the e-Commerce adoption scores (to be maximized) in the second level of the bi-level fishbone diagram through the TOPSIS Formulas (7)-(9) given below:

$$
T_{i_{j} h_{1} h_{1}}=\frac{D_{i_{1} j_{1} h_{1}}^{-}}{D_{i_{1} j_{1} h_{1}}^{*}+D_{i_{1} j_{1} h_{1}}^{-}}
$$

where $0 \leq T_{i_{1} j_{1} h_{1}} \leq 1$ and

$$
\begin{aligned}
D_{i_{1} j_{1} h_{1}}^{*}=( & E\left[\tilde{w}\left(x_{1}\right)\right] \cdot E\left[\tilde{w}\left[e_{1}\left(x_{1}\right)\right]\right] \cdot E\left[\tilde{a}_{i_{1} j_{1} h_{1}}\left[e_{1}\left(x_{1}\right)\right]-\tilde{a}^{*}\left[e_{1}\left(x_{1}\right)\right]\right]^{2} \\
& \left.+\cdots+E\left[\tilde{w}\left(x_{n}\right)\right] \cdot E\left[\tilde{w}\left[e_{m_{n}}\left(x_{n}\right)\right]\right] \cdot E\left[\tilde{a}_{i_{1} j_{1} h_{1}}\left[e_{m_{n}}\left(x_{n}\right)\right]-\tilde{a}^{*}\left[e_{m_{n}}\left(x_{n}\right)\right]\right]^{2}\right)^{1 / 2} \\
D_{i_{1} j_{1} h_{1}}^{-}= & \left(E\left[\tilde{w}\left(x_{1}\right)\right] \cdot E\left[\tilde{w}\left[e_{1}\left(x_{1}\right)\right]\right] \cdot E\left[\tilde{a}_{i_{1} j_{1} h_{1}}\left[e_{1}\left(x_{1}\right)\right]-\tilde{a}^{-}\left[e_{1}\left(x_{1}\right)\right]\right]^{2}\right. \\
& \left.+\cdots+E\left[\tilde{w}\left(x_{n}\right)\right] \cdot E\left[\tilde{w}\left[e_{m_{n}}\left(x_{n}\right)\right]\right] \cdot E\left[\tilde{a}_{i_{1} j_{1} h_{1}}\left[e_{m_{n}}\left(x_{n}\right)\right]-\tilde{a}^{-}\left[e_{m_{n}}\left(x_{n}\right)\right]\right]^{2}\right)^{1 / 2}
\end{aligned}
$$

The highest relative closeness score is 1 that shows the best e-Commerce maturity stage where $D_{i_{1}, h_{1} h_{1}}^{*}=0$ and $D_{i_{1, j} h_{1}}^{-}=8$. In contrast, the lowest relative closeness score is 0 that shows the e-Commerce adoption stage where $D_{i_{1}, h_{1} h_{1}}^{*}=8$ and $D_{i_{1}, h_{h_{1}} h_{1}}^{-}=0$.

Level 1: National e-Market

$$
\begin{aligned}
& M a x F_{1}^{1}=Z_{1}(1)+2 Z_{1}(2)+3 Z_{1}(3)+4 Z_{1}(4)+5 Z_{1}(5) \\
& S t: 0 \leq \sum_{j_{1}=1}^{51} E\left[\tilde{w}_{i_{1} j_{1}} \cdot \tilde{d}_{j_{1} j_{1}}\left(y_{i_{1}}\right)\right] \cdot F_{i_{1} j_{1}}^{2}+\sum_{i_{1}^{\prime}=1}^{44} \frac{\tilde{d}_{1 i_{1}^{\prime}}}{44} \leq 0.1+M \times Z_{1}(1) \\
& \vdots \\
& 0.9-M \times Z_{1}(5) \leq \sum_{j_{1}=1}^{51} E\left[\tilde{w}_{i_{1} j_{1}} \cdot \tilde{d}_{i_{1} j_{1}^{\prime}}\left(y_{1}\right)\right] \cdot F_{1 j_{1}}^{2}+\sum_{i_{1}^{\prime}=1}^{44} \frac{\tilde{d}_{1 i_{1}^{\prime}}}{44} \leq 1+M \times Z_{1}(5) \\
& Z_{1}(1)+Z_{1}(2)+Z_{1}(3)+Z_{1}(4)+Z_{1}(5)=4 \\
& Z_{1}(1), Z_{1}(2), Z_{1}(3), Z_{1}(4), Z_{1}(5)=0,1
\end{aligned}
$$

(The proposed three-level decision making model)

Level 2: Regional e-Market

$$
\begin{gathered}
\operatorname{Max}_{1 j_{1}}^{2}=Z_{1 j_{1}}(1)+2 Z_{1 j_{1}}(2)+3 Z_{1 j_{1}}(3)+4 Z_{1 j_{1}}(4)+5 Z_{1 j_{1}}(5) \\
S t: 0 \leq \sum_{h_{1}=1}^{q_{j_{1}}} E\left[\tilde{w}_{i_{1} j_{1} h_{1}} \cdot \tilde{d}_{h_{1} h_{1}^{\prime}}\left(s_{j_{1}}\right)\right] \cdot F_{1 j_{1} h_{1}}^{3} \leq 0.1+M \times Z_{1 j_{1}}(1) \\
\vdots \\
0.9-M \times Z_{1 j_{1}}(5) \leq \sum_{h_{1}=1}^{q_{j_{1}}} E\left[\tilde{w}_{i_{j_{1} h_{1}} h_{1}} \cdot \tilde{d}_{h_{1} h_{1}}\left(s_{j_{1}}\right)\right] \cdot F_{1 j_{1} h_{1}}^{3} \leq 1+M \times Z_{1 j_{1}}(5) \\
Z_{1 j_{1}}(1)+Z_{1 j_{1}}(2)+Z_{1 j_{1}}(3)+Z_{1 j_{1}}(4)+Z_{1 j_{1}}(5)=4 \\
Z_{1 j_{1}}(1), Z_{1 j_{1}}(2), Z_{1 j_{1}}(3), Z_{1 j_{1}}(4), Z_{1 j_{1}}(5)=0,1
\end{gathered}
$$

Level 3: Local e-Market 


$$
\begin{aligned}
& M a x F_{1 j_{1} h_{1}}^{3}=Z_{1 j_{1} h_{1}}(1)+2 Z_{1 j_{1} h_{1}}(2)+3 Z_{1 j_{1} h_{1}}(3)+4 Z_{1 j_{1} h_{1}}(4)+5 Z_{1 j_{1} h_{1}}(5) \\
& S t: 0 \leq T_{i_{1} j_{1} h_{1}} \leq 0.1+M \times Z_{1 j_{1} h_{1}}(1) \\
& \quad \vdots \\
& 0.9-M \times Z_{1 j_{1} h_{1}}(5) \leq T_{i_{1} h_{1} h_{1}} \leq 1+M \times Z_{1 j_{1} h_{1}}(5) \\
& Z_{1 j_{1} h_{1}}(1)+Z_{1 j_{1} h_{1}}(2)+Z_{1 j_{1} h_{1}}(3)+Z_{1 j_{1} h_{1}}(4)+Z_{1 j_{1} h_{1}}(5)=4 \\
& Z_{1 j_{1} h_{1}}(1), Z_{1 j_{1} h_{1}}(2), Z_{1 j_{1} h_{1}}(3), Z_{1 j_{1} h_{1}}(4), Z_{1 j_{1} h_{1}}(5)=0,1
\end{aligned}
$$

where: $M$ is a large number.

Procedure 3.1.2: Calculate the fuzzy e-Commerce maturity score for each local e-Market without considering local e-Markets interdependencies

In this procedure, after defining stages of e-Commerce maturity (see Table 8), the optimal solution of the third level of the following proposed three-level model determines the fuzzy e-Commerce maturity scores for the local e-Markets without considering local e-Markets interdependencies.

Process 3.2: Determine an e-Commerce maturity stage for each regional e-Market

The optimal solution of the second level of the proposed fuzzy three-level decision making model determines the e-Commerce maturity stage of the regional e-Markets.

Process 3.3: Determine country's e-Commerce maturity stage

The optimal solution of the first level of the proposed fuzzy three-level decision making model determines country’s e-Commerce maturity stage.

\section{Case Study}

In order to determine national e-Commerce maturity stage in goods and services, the proposed framework in this study has been utilized as follows:

In the first phase, the fuzzy bi-level fishbone diagram was drawn (See Figure 4).

This diagram consisted of four criteria and each of the four criteria was divided into the following sub-criterion elements: G2G, G2B, G2E, G2C, B2G, B2E, B2C, C2G, $\mathrm{C} 2 \mathrm{~B}$, and $\mathrm{C} 2 \mathrm{E}$.

In the second phase, the fuzzy e-Commerce maturity self-assessment scores were calculated (See Figure 5).

In the third phase, five stages of e-Commerce maturity were defined as follows (see Table 9):

Finally, the stage of US e-Commerce maturity was determined using the following fuzzy three-level decision making model.

Level 1: National e-Market

$$
\begin{aligned}
& \operatorname{MaxF}_{1}^{1}=Z_{1}(1)+2 Z_{1}(2)+3 Z_{1}(3)+4 Z_{1}(4)+5 Z_{1}(5) \\
& S t: 0 \leq \sum_{j_{1}=1}^{51} E\left[\tilde{w}_{i_{1} j_{1}} \cdot \tilde{d}_{j_{1} j_{1}}\left(y_{i_{1}}\right)\right] \cdot F_{i_{1} j_{1}}^{2}+\sum_{i_{1}^{\prime}=1}^{44} \frac{\tilde{d}_{1 i_{1}^{\prime}}}{44} \leq 0.1+M \times Z_{1}(1) \\
& \vdots \\
& 0.9-M \times Z_{1}(5) \leq \sum_{j_{1}=1}^{51} E\left[\tilde{w}_{i_{1} j_{1}} \cdot \tilde{d}_{j_{1} j_{1}^{\prime}}\left(y_{1}\right)\right] \cdot F_{1 j_{1}}^{2}+\sum_{i_{1}^{\prime}=1}^{44} \frac{\tilde{d}_{1 i_{1}^{\prime}}}{44} \leq 1+M \times Z_{1}(5) \\
& Z_{1}(1)+Z_{1}(2)+Z_{1}(3)+Z_{1}(4)+Z_{1}(5)=4 \quad Z_{1}(1), Z_{1}(2), Z_{1}(3), Z_{1}(4), Z_{1}(5)=0,1
\end{aligned}
$$

(The proposed three-level decision making model)

Level 2: Regional e-Market

$$
\begin{gathered}
\operatorname{MaxF}_{1 j_{1}}^{2}=Z_{1 j_{1}}(1)+2 Z_{1 j_{1}}(2)+3 Z_{1 j_{1}}(3)+4 Z_{1 j_{1}}(4)+5 Z_{1 j_{1}}(5) \\
S t: 0 \leq \sum_{h_{1}=1}^{q_{j_{1}}} E\left[\tilde{w}_{i_{1} h_{1} h_{1}} \cdot \tilde{d}_{h_{1} h_{1}}\left(s_{j_{1}}\right)\right] \cdot F_{1 j_{1} h_{1}}^{3} \leq 0.1+M \times Z_{1 j_{1}}(1) \\
\vdots \\
0.9-M \times Z_{1 j_{1}}(5) \leq \sum_{h_{1}=1}^{q_{j_{1}}} E\left[\tilde{w}_{i_{1} h_{1} h_{1}} \cdot \tilde{d}_{h_{1} h_{1}^{\prime}}\left(s_{j_{1}}\right)\right] \cdot F_{1 j_{1} h_{1}}^{3} \leq 1+M \times Z_{1 j_{1}}(5) \\
Z_{1 j_{1}}(1)+Z_{1 j_{1}}(2)+Z_{1 j_{1}}(3)+Z_{1 j_{1}}(4)+Z_{1 j_{1}}(5)=4 \quad Z_{1 j_{1}}(1), Z_{1 j_{1}}(2), Z_{1 j_{1}}(3), Z_{1 j_{1}}(4), Z_{1 j_{1}}(5)=0,1
\end{gathered}
$$




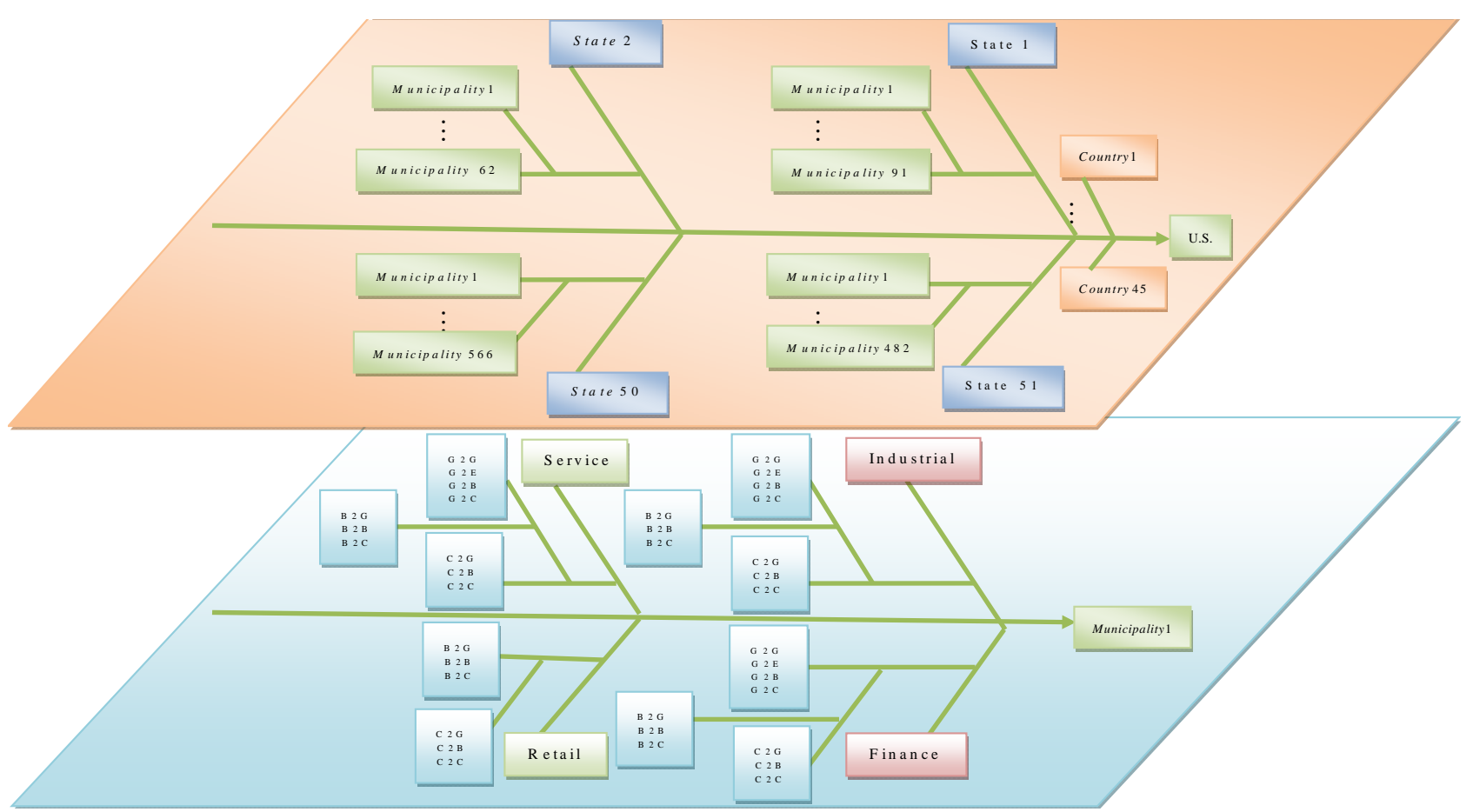

Figure 4. The e-Commerce maturity self-assessment criteria and sub-criteria in U.S.

Level 3: Local e-Market

$$
\begin{gathered}
\operatorname{MaxF}_{1 j_{1} h_{1}}^{3}=Z_{1 j_{1} h_{1}}(1)+2 Z_{1 j_{1} h_{1}}(2)+3 Z_{1 j_{1} h_{1}}(3) \\
+4 Z_{1 j_{1} h_{1}}(4)+5 Z_{1 j_{1} h_{1}}(5) \\
S t: 0 \leq T_{i_{1} j_{1} h_{1}} \leq 0.1+M \times Z_{1 j_{1} h_{1}}(1) \\
\vdots \\
0.9-M \times Z_{1 j_{1} h_{1}}(5) \leq T_{i_{1} j_{1} h_{1}} \leq 1+M \times Z_{1 j_{1} h_{1}}(5) \\
Z_{1 j_{1} h_{1}}(1)+Z_{1 j_{1} h_{1}}(2)+Z_{1 j_{1} h_{1}}(3)+Z_{1 j_{1} h_{1}}(4)+Z_{1 j_{1} h_{1}}(5)=4 \\
Z_{1 j_{1} h_{1}}(1), Z_{1 j_{1} h_{1}}(2), Z_{1 j_{1} h_{1}}(3), Z_{1 j_{1} h_{1}}(4), Z_{1 j_{1} h_{1}}(5)=0,1
\end{gathered}
$$

Table 8. National e-Commerce maturity stages.

\begin{tabular}{cc}
\hline Maturity Stage & Score \\
\hline 1 & $0-g_{l_{1}}$ \\
2 & $g_{l_{1}}-g_{l_{2}}$ \\
$\vdots$ & $\vdots$ \\
N & $g_{l_{(n-1)}}-g_{l_{n}}$ \\
\hline
\end{tabular}

Table 9. E-Commerce maturity stages.

\begin{tabular}{ccc}
\hline Stage & Maturity Stage & Score \\
\hline 1 & Does not Exist & $0.0-0.1$ \\
2 & Functional & $0.1-0.3$ \\
3 & Competitive & $0.4-0.6$ \\
4 & Advanced & $0.7-0.9$ \\
5 & Best in Class & $0.9-1.0$ \\
\hline
\end{tabular}

After determining the final US e-Commerce maturity stages of the municipalities and states shown in the third and second levels of the above three-level model, the optimal solution of the first level of the three-level selfassessment model showed the four e-Commerce maturity stage as and US e-Commerce maturity stage.

\section{Conclusion}

We developed a country-level decision making framework to determine maturation stage of e-Commerce in a country. For this purpose, we defined interdependencies between local, regional and international e-Markets. Then, e-Commerce maturity scores of local e-Markets in a country were calculated using a fuzzy bi-level TOPSIS method. It synthesized qualitative judgments and quantitative data of maturity criteria and sub-criteria. After that, the fishbone diagram was developed to a fuzzy bi-level fishbone diagram to determine e-Commerce maturity 


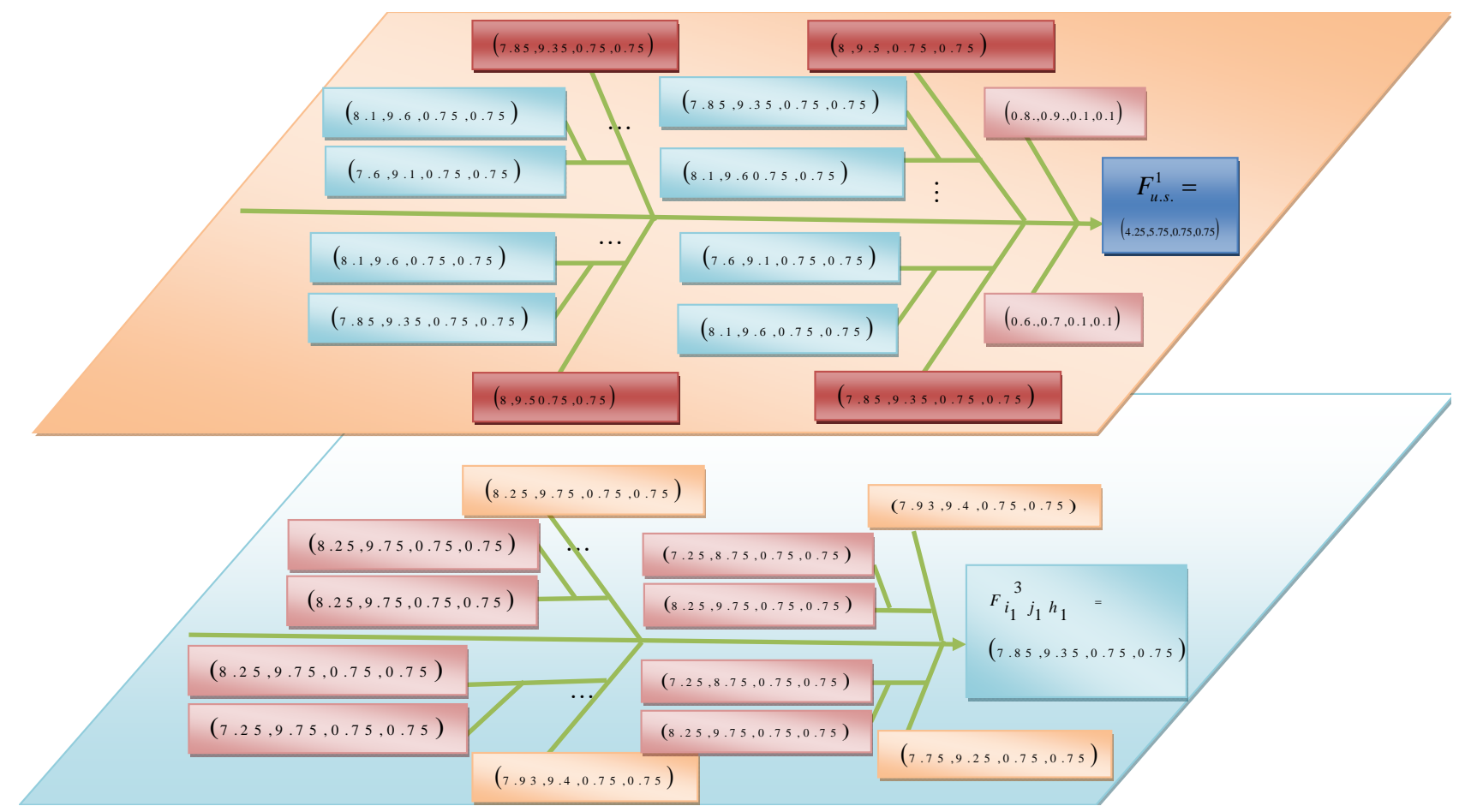

Figure 5. The fuzzy e-Commerce maturity self-assessment scores in U.S.

scores of regional and national e-Markets in the country. Finally, a three-level decision making model was used to assess e-Commerce maturity level. The results of this country-level self-assessment framework were suggested to analyze e-Commerce SWOT where a country is on their journey towards excellence. A case study was presented to determine e-Commerce maturity level in U.S.

\section{Acknowledgements}

This research was supported by SCIRP grant. The author is grateful to the SCIRP Editorial Board for assistance with this research. The author would like to thank the anonymous reviewers for their insightful comments and suggestions.

\section{REFERENCES}

[1] G. C. Ariguzo, E. G. Mallach and D. S. White, "The First Decade of E-Commerce," International Journal of Business Information Systems, Vol. 1, No. 3, 2006, pp. 239255.

[2] H. Barry and B. Milner, "SME's and Electronic Commerce: A Departure from the Traditional Prioritization of Training?” Journal of European Industrial Training, Vol. 26, No. 7, 2002, pp. 316-326. doi:10.1108/03090590210432660

[3] P. Barnes-Vieyra and C. Claycomb, "Business-To-Business E-Commerce: Models and Managerial Decisions,” Business Horizons, Vol. 44, No. 3, 2001, pp. 13-20. doi:10.1016/S0007-6813(01)80030-6

[4] J. L. Gibbs and K. L. Kraemer, "A Cross-Country Investigation of the Determinants of Scope of E-Commerce
Use: An Institutional Approach,” Electronic Markets, Vol. 14, No. 2, 2004, pp. 124-137. doi:10.1080/10196780410001675077

[5] J. Jeffcoate, C. Chappell and S. Feindt, "Best Practice in SME Adoption of E-Commerce," Benchmarking: An International Journal, Vol. 9, No. 2, 2002, pp. 122-132.

[6] N. Karagozoglu and M. Lindell, "Electronic Commerce Strategy, Operations, and Performance in Small and Medium-Sized Enterprises," Journal of Small Business and Enterprise Development, Vol. 11, No. 3, 2004, pp. 290301. doi:10.1108/14626000410551555

[7] C. S. Lee, "An Analytical Framework for Evaluating E-Commerce Business Models and Strategies,” Internet Research: Electronic Network Applications and Policy, Vol. 11, No. 4, 2001, pp. 349-359. doi:10.1108/10662240110402803

[8] A. Molla and P. S. Licker, "Perceived E-Readiness Factors in E-Commerce Adoption: An Empirical Investigation in a Developing Country," International Journal of Electronic Commerce, Vol. 10, No. 1, 2005, pp. 83-110.

[9] M. Garcia-Murillo, "Institutions and the Adoption of Electronic Commerce in Mexico,” Electronic Commerce Research, Vol. 4, No. 3, 2004, pp. 201-219. doi:10.1023/B:ELEC.0000027980.16492.af

[10] S. Hawk, "A Comparison of B2C E-Commerce in Developing Countries," Electronic Commerce Research, Vol. 4, No. 3, 2004, pp. 181-199. doi:10.1023/B:ELEC.0000027979.91972.36

[11] R. Javalgi and R. Ramsey, "Strategic Issues of E-Commerce as an Alternative Global Distribution System," International Marketing Review, Vol. 18, No. 4, 2001, pp. 376-391. doi:10.1108/02651330110398387 
[12] J. E. Oxley and B. Yeung, "E-Commerce Readiness: Institutional Environment and International Competitiveness,” Journal of International Business Studies, Vol. 32, No. 4, 2001, pp. 705-723.

[13] P. A. Pavlou, "Consumer Acceptance of Electronic Commerce: Integrating Trust and Risk with the Technological Acceptance Model,” International Journal of Electronic Commerce, Vol. 7, No. 3, 2003, pp. 101-134.

[14] S. Solaymani, K. Sohaili and E. A. Yazdinejad, "Adoption and Use of E-Commerce in SMEs: A Case Study," Electronic Commerce Research, Vol. 12, No. 3, 2012, pp. 249-263. doi:10.1007/s10660-012-9096-6

[15] S. A. Wymer and E. A. Regan, "Factors Influencing ECommerce Adoption and Use by Small and Medium Businesses,” Electronic Markets, Vol. 15, No. 4, 2005, pp. 438-453. doi:10.1080/10196780500303151

[16] KPMJ, "Electronic Commerce Research Report,” London, 1997.

[17] S. Grant, "E-Commerce for Small Businesses, Innovation through Electronic Commerce," Proceedings of the 2nd International Conference, Manchester, 1999.

[18] J. McKay, "E-Business Maturity: The SOG-E Model," Proceedings of the 11th Australasian Conference on Information Systems, Brisbane, 6-8 December 2000, pp. $1-3$.

[19] M. J. Earl, "Evolving the E-Business,” Business Strategy Review, Vol. 11, No. 2, 2000, pp. 33-38. doi:10.1111/1467-8616.00135

[20] A. Prananto, et al. "Frameworks to Support E-Business Growth Strategy," The 9th European Conference on Information Systems, Bled, 27-29 June 2001, pp. 12541263.

[21] J. F. Rayport and B. J. Jaworski, "Introduction to E-Commerce,” McGraw-Hill, New York, 2002.

[22] S. Rao, "Electronic Commerce Developmentt in Small and Medium Sized Enterprises: A Stage Model and Its Implications," Business Process Management Journal, Vol. 9, No. 1, 2003, pp. 11-32. doi:10.1108/14637150310461378

[23] C. Chan and P. Swatman, "B2B E-Commerce Stages of Growth: The Strategic Imperatives,” Proceedings of the 37th Hawaii International Conference on Systems Science, Hawaii, 5-8 January 2004, pp. 1-10.

[24] F. Balbastre, M. Moreno-Luzón, "Self-Assessment Application and Learning in Organizations: A Special Reference to the Ontological Dimension,” Total Quality Management \& Business Excellence, Vol. 14, No. 3, 2003, pp. 367-388. doi:10.1080/1478336032000046661

[25] K. S. Chin, K. F. Pun and H. Lau, "Development of a Knowledge-Based Self-Assessment System for Measuring Organizational Performance," Expert Systems with Applications, Vol. 24, No. 4, 2003, pp. 443-455. doi:10.1016/S0957-4174(02)00192-6

[26] T. Conti, “Optimizing Self-Assessment,” Total Quality Management, Vol. 8, No. 2-3, 1997, pp. 5-15. doi:10.1080/0954412979640

[27] Y. Politis and Y. Siskos, "Self-Assessment for Measuring Business Excellence: The MUSABE Method," Total
Quality Management \& Business Excellence, Vol. 21, No. 11, 2010, pp. 1063-1083.

[28] L. Ritchie and B. G. Dale, "Self-assessment Using the Business Excellence Model: A Study of Practice and Process," International Journal of Production Economics, Vol. 66, No. 3, 2000, pp. 241-254. doi:10.1016/S0925-5273(99)00130-9

[29] J. Sturkenboom, T. Wiele and A. Brown, “An ActionOriented Approach to Quality Management Self-Assessment in Small and Medium-Sized Enterprises,” Total Quality Management, Vol. 12, No. 2, 2001, pp. 231-246. doi:10.1080/09544120120011451

[30] C. G. Reddick, "Government E-Commerce Adoption: A Study of Texas Counties," Journal of E-Government, Vol. 2, No. 2, 2006, pp. 45-73. doi:10.1300/J399v02n02_04

[31] M. Quayle, "E-commerce: The Challenge for UK SMEs in the 21st Century," International Journal of Operations and Production Management, Vol. 22, No. 10, 2002, pp. 1148-1161. doi:10.1108/01443570210446351

[32] P. B. Tigre and J. Dedrick, "E-Commerce in Brazil: Local Adaptation of a Global Technology,” Electronic Markets, Vol. 14, No. 1, 2004, pp. 36-47. doi:10.1080/1019678042000175289

[33] P. Hadaya, "Determinants of the Future Level of Use of Electronic Marketplaces: The Case of Canadian Firms," Electronic Commerce Research, Vol. 6, No. 2, 2006, pp. 173-185. doi:10.1007/s10660-006-6956-y

[34] D. Buhalis and O. Deimezi, "Information Technology Penetration and E-Commerce Developments in Greece, with a Focus on Small to Medium-Sized Enterprises,” Electronic Markets, Vol. 13, No. 4, 2003, pp. 309-324. doi:10.1080/1019678032000135563

[35] H. Lee, R. M. O’Keefe and K. Yun, “The Growth of Broadband and Electronic Commerce in South Korea: Contributing Factors,” The Information Society, Vol. 19, No. 1, 2003, pp. 81-93. doi:10.1080/01972240309470

[36] C. B. Kheng and S. Al-Hawamdeh, "The Adoption of Electronic Procurement in Singapore," Electronic Commerce Research, Vol. 2, No. 1-2, 2002, pp. 61-73. doi:10.1023/A:1013388018056

[37] T. Teo and C. Ranganathan, "Adopters and Non-Adopters of Business-to-Business Electronic Commerce in Singapore," Information and Management, Vol. 42, No. 1, 2004, pp. 89-102. doi:10.1016/j.im.2003.12.005

[38] P. Wong, "Global and National Factors Affecting E-Commerce Diffusion in Singapore,” The Information Society, Vol. 19, No. 1, 2003, pp. 19-32. doi:10.1080/01972240309471

[39] J. Ure, "Modeling Critical Mass for E-Commerce: The Case of Hong Kong," Electronic Commerce Research, Vol. 2, No. 1-2, 2002, pp. 87-111. doi:10.1023/A:1013344219873

[40] S. Chen and J. Ning, "Constraints on E-Commerce in Less Developed Countries: The Case of China," Electronic Commerce Research, Vol. 2, No. 1-2, 2002, pp. 31-42. doi:10.1023/A:1013331817147

[41] J. Lu, L. -Z. Wang, C. -S. Yu and J. -Y. Wu, "E-Auction Web Assessment Model in China,” Electronic Commerce 
Research, Vol. 9, No. 3, 2009, pp. 149-172. doi:10.1007/s10660-009-9033-5

[42] K. Reimers and G. Chen, “A Multi-Level Approach for Devising Effective B2B E-Commerce Development Strategies with an Application to the Case of China," Electronic Commerce Research, Vol. 4, No. 3, 2004, pp. 287305. doi:10.1023/B:ELEC.0000027984.15737.cb

[43] C. V. Trappey and A. J. Trappey, "Electronic Commerce in Greater China,” Industrial Management and Data Systems, Vol. 101, No. 5, 2001, pp. 201-209. doi:10.1108/02635570110394617

[44] P. Dasgupta and K. Sengupta, "E-Commerce in the Indian Insurance Industry: Prospects and Future," Electronic Commerce Research, Vol. 2, No. 1-2, 2002, pp. 43-60.

[45] T. T. Le and A. C. Koh, "A Managerial Perspective on Electronic Commerce Development in Malaysia," Electronic Commerce Research, Vol. 2, No. 1-2, 2002, pp. 729. doi:10.1023/A:1013318016239

[46] K. Narayanasamy, D. Rasiah and T. M. Tan, “The Adoption and Concerns of E-Finance in Malaysia," Electronic Commerce Research, Vol. 11, No. 4, 2011, pp. 383-400. doi:10.1007/s10660-011-9081-5

[47] J. Fisher, A. Craig and J. Bentley, "Moving from a Web Presence to E-Commerce: The Importance of a BusinessWeb Strategy for Small-Business Owners,” Electronic
Markets, Vol. 17, No. 4, 2007, pp. 253-262. doi:10.1080/10196780701635864

[48] R. Boatenga, R. Hinson, R. Heeks and A. Molla, "ECommerce in Least Developing Countries: Summary Evidence and Implications,” Journal of African Business, Vol. 9, No. 2, 2008, pp. 257-285.

doi:10.1080/15228910802479919

[49] J. L. Gibbs, K. L. Kraemer and J. Dedrick, "Environment and Policy Factors Shaping Global E-Commerce Diffusion: A Cross-Country Comparison,” The Information Society: An International Journal, Vol. 19, No. 1, 2003, pp. 5-18.

[50] M. E. Jennex, D. Amoroso and O. Adelakun, "E-Commerce Infrastructure Success Factors for Small Companies in Developing Economies,” Electronic Commerce Research, Vol. 4, No. 3, 2004, 263-286. doi:10.1023/B:ELEC.0000027983.36409.d4

[51] D. Kao and J. Decou, "A Strategy-Based Model for ECommerce Planning," Industrial Management and Data Systems, Vol. 103, No. 4, 2003, pp. 238-252. doi:10.1108/02635570310470638

[52] N. B. Kshetri, "Determinants of the Locus of Global ECommerce,” Electronic Markets, Vol. 11, No. 4, 2001, pp. 250-257. 